\title{
Disposal Criticality Analysis Methodology: BWR Benchmarks
}

\section{P. Henderson, Framatome Cogema Fuels, Las Vegas}

D. A. Salmon, Framatome Cogema Fuels, Las Vegas

\section{Introduction}

Computer code benchmarks using commercial reactor critical (CRC) data for boiling water reactor (BWR) fuel assemblies using the SCALE and MCNP code packages have been conducted: Depleted fuel inventories which take into account actinide and fission product concentrations are used to develop reactor critical models and the associated neutron multiplication factors. Bias calculated from this integral benchmark method will be applied to the disposal criticality analysis methodology to ensure the sub-criticality of spent commercial nuclear fuel forecast for emplacement into the proposed geologic repository at Yucca Mountain. Previous CRC benchmark calculations have been performed for startup tests for Cycles 13 and 14 of the Quad Cities Unit 2 BWR ${ }^{1}$. Additional benchmarking activities have been performed and applied to evaluations of beginning-of-cycle (BOC) reactor critical models for Cycles 7 and 8 of the LaSalle Unit 1 BWR.

Similar to the methodology used for ensuring sub-critical margin for spent nuclear fuel shipping casks, the proposed criticality analysis approach computes the neutron multiplication factor of arbitrary fuel assemblies placed in spent fuel waste packages that represents a bounding criticality model. ${ }^{2}$ This is accomplished by calculating spent fuel inventories with the SAS2H sequence of the SCALE code package ${ }^{3}$ and computing the neutron multiplication of the spent fuel assemblies in the waste package with $\mathrm{MCNP}^{4}$.

\section{Description of Benchmark Method}

Benchmark calculations for the SCALE and MCNP code packages have been performed for the aforementioned reactor startup tests to support the development of a bias function to be used in the criticality analysis methodology. To perform the SAS2H fuel depletion calculations, control blade insertion times, nodal exposure increments, nodal average fuel temperatures, and nodal void fractions were obtained from utility core-follow calculations. Along with fuel geometrical design information and initial fissile loadings, this information permitted computation of exposed fuel isotopic inventories for the participating fuel assemblies. While the nodal exposures 
and void fractions were available in 24 and 25 axial nodes, these data were collapsed a corresponding 10 axial node format of non-uniform length to reduce computing resource requirements.

After exposed fuel inventories were calculated with SAS2H, the distributions of actinide and fission product inventories used in critical models were varied using four inventory models:

- Best-Estimate: all actinides and fission products with nuclear data representations available in MCNP were considered;

- Principal Isotopes: limited to the 14 actinides and 15 fission products specified in the proposed methodology;

- Principal Actinides: the "Principal Isotope" list less the fission products; and

- Actinide Only: the actinides considered in the criticality methodology for transportation. ${ }^{5}$

MCNP CRC calculations with fresh and exposed fuel inventories for each reactor were performed assuming a quarter core with reflective symmetry. Because BWR CRC benchmarks require large computer models and are CPU intensive, the SAS2H fuel depletion calculations were performed on an assembly nodal basis. These nodal spent fuel inventories were uniformly allocated (homogenized) to the fuel rods in an MCNP node even though the lattice geometry was explicitly modeled. To evaluate the impact of smearing fresh fuel gadolinia isotopic concentrations evenly throughout the nodal models, additional MCNP CRC cases were developed which placed gadolinia isotopes in a homogenized fuel model for fresh fuel nodes.

\section{Results}

The results for the MCNP reactivity calculations for LaSalle startup tests are shown in Table 1. Good agreement was obtained for the best estimate critical calculations. The degree of overprediction indicated for each of the four isotopic inventory options is consistent with the expectations for the appropriate isotopic compositions. The gadolinia placement in the critical model has a significant impact on the results, and is consistent with the strong self-shielding characteristics expected of gadolinia in fuel rods.

Current BWR CRC benchmark activities include assessing the effects of variations in control blade models during SAS2H calculations of exposed fuel inventories. The concentrations 
of fissile materials in the fuel inventory are strongly affected by shifts in the neutron energy spectrum caused by the presence of control blades during depletion.

Table 1. MCNP Results for BWR Critical Experiments

\begin{tabular}{|c|c|c|}
\hline Identifier & $\begin{array}{c}\text { Multiplication factor } \\
\mathbf{k}_{\text {eff }}\end{array}$ & $\begin{array}{c}\text { Uncertainty } \\
\sigma\end{array}$ \\
\hline \multicolumn{3}{|l|}{ Best Estimate } \\
\hline LS1BOC7[a] & 1.00309 & 0.00045 \\
\hline LS1BOC7[b] & 0.96776 & 0.00030 \\
\hline LS1BOC7[C] & 1.00299 & 0.00035 \\
\hline LS1BOC7[d] & 0.96559 & 0.00030 \\
\hline LS1BOC8[a] & 1.00151 & 0.00028 \\
\hline LS1BOC8[b] & 0.90504 & 0.00037 \\
\hline LS1BOC8[C] & 1.00096 & 0.00032 \\
\hline LS1BOC8[d] & 0.89610 & 0.00034 \\
\hline \multicolumn{3}{|l|}{ Principal Isotope } \\
\hline LS1BOC7[a] & 1.01443 & 0.00044 \\
\hline LS1BOC8[a] & 1.00882 & 0.00031 \\
\hline \multicolumn{3}{|c|}{ Principal Actinide } \\
\hline LS1BOC7[a] & 1.05548 & 0.00054 \\
\hline LS1BOC8[a] & 1.04254 & 0.00032 \\
\hline \multicolumn{3}{|l|}{ Actinide Only } \\
\hline LS1BOC7[a] & 1.05693 & 0.00051 \\
\hline LS1BOC8[a] & 1.04385 & 0.00033 \\
\hline
\end{tabular}

Nodal Treatments in MCNP Models:
[a]. Discrete Fresh Fuel
[b]. Smeared Fresh Fuel
[c]. Discrete Fresh Fuel Without Control Blades
[d]. Smeared Fresh Fuel Without Control Blades 


\section{References}

1 Anderson, M.J. and Henderson, D.P., BWR Benchmarking for Yucca Mountain Disposal Criticality Methodology, American Nuclear Society Transactions, Vol. 79, November 1998.

2 Disposal Criticality Analysis Methodology Technical Report, DI: B00000000-01717-570500020 REV 01, DOE OCRWM, September 4, 1997.

3 SCALE 4.3, Modular Code System for Performing Standardized Computer Analysis for Licensing Evaluation, ORNL/NUREG/CDS-2/N2/R5, Oak Ridge National Laboratory, September 1995.

4 Briesmeister, J. F., Ed., MCNP ${ }^{\mathrm{TM}}-$ A General Monte Carlo N-Particle Transport Code, Version 4B, LA-12625-M, Los Alamos National Laboratory (LANL), March 1997.

5 Topical Report on Actinide-Only Burnup Credit for PWR Spent Nuclear Fuel Packages, DOE/RW-0472, DOE OCRWM, Washington, DC, May 1997. 